\title{
OPTIMAL EXERCISE PRICES FOR EXECUTIVE STOCK OPTIONS
}

\author{
Brian J. Hall \\ Kevin J. Murphy \\ Working Paper 7548 \\ http://www.nber.org/papers/w7548 \\ NATIONAL BUREAU OF ECONOMIC RESEARCH \\ 1050 Massachusetts Avenue \\ Cambridge, MA 02138 \\ February 2000
}

We thank Harry DeAngelo, Linda DeAngelo and John Matsusaka for valuable comments. The spreadsheets and macros used in this article are available from the authors at www-rcf.usc.edu/ kjmurphy. The views expressed herein are those of the authors and not necessarily those of the National Bureau of Economic Research.

(C) 2000 by Brian J. Hall and Kevin J. Murphy. All rights reserved. Short sections of text, not to exceed two paragraphs, may be quoted without explicit permission provided that full credit, including $(\mathcal{C}$ notice, is given to the source. 
Optimal Exercise Prices for Executive Stock Options

Brian J. Hall and Kevin J. Murphy

NBER Working Paper No. 7548

February 2000

JEL No. J0, J3, G0, G3

\begin{abstract}
Although exercise prices for executive stock options can be set either below or above the grant-date market price, in practice virtually all options are granted at the money. We offer an economic rationale for this apparent puzzle, by showing that pay-to-performance incentives for riskaverse, undiversified executives are typically maximized by setting exercise prices at (or near) the grant-date market price. We provide an operationally useful alternative to Black-Scholes (1973) for the purpose of both valuing executive stock options and measuring the incentives created by options. Our framework has implications not only for exercise-price policies, but also for indexed options, option repricings, exchanges of cash for stock-based compensation, and the design of bonus plans.
\end{abstract}

Brian J. Hall

Harvard Business School

Soldiers Field

Boston, MA 02163

and NBER

bhall@hbs.edu
Kevin J. Murphy

USC

Marshall School of Business

MC 1427

Los Angeles, CA 90089-1427

kjmurphy@usc.edu 
Stock options, which give the recipient the right to buy a share of stock at a prespecified "exercise" price for a pre-specified term, have emerged as the single largest component of compensation for US executives (Brian J. Hall and Jeffrey Liebman, 1998). In fiscal 1998, the grant-date value of stock options accounted for $40 \%$ of total pay for S\&P 500 CEOs, up from only $25 \%$ of total pay in $1992 .{ }^{1}$ Stock-options have become increasingly important for rank-and-file workers as well: $45 \%$ of US companies awarded options to their exempt salaried employees in 1998 , while $12 \%$ and $10 \%$ awarded options to their nonexempt and hourly employees, respectively. ${ }^{2}$

One of the most striking facts about executive stock options is that the exercise price of virtually all options is set equal to the current stock price at the grant date. For example, $94 \%$ of option grants to S\&P 500 CEOs in 1998 were at-the-money grants. In theory, exercise prices can be set below the grant-date stock price (discount options), above the grant-date stock price (premium options), or indexed to some industry or market index (indexed options). Premium and indexed options have strong proponents (e.g., Alfred Rappaport, 1999), who argue that discount and at-the-money options create huge rewards for belowmarket performance, especially during a bull market.

Exercise-price policy is perhaps the central design issue regarding options. Setting the exercise price, like setting the "performance threshold" in any incentive plan, defines the standard against which performance is measured, and determines the likelihood of an ultimate payout. To our knowledge, no one has advanced a convincing (or even

1 Data extracted from Compustat's ExecuComp database, using grant-date option values based on ExecuComp's Black-Scholes' calculations.

2 Prevalence data are based on the American Compensation Association's 1997-1998 Salary Budget Survey, and include survey results from 735 publicly traded corporations. 
unconvincing) economic rationale for the near-uniform practice of issuing options at-themoney. Accounting and tax considerations may explain why discount and indexed options are unpopular, but do not explain the paucity of premium options. ${ }^{3}$ And, while inertia and corporate conformity ("mimicry") can explain why policies are similar across companies, we would not expect the observed practice to sustain itself in the long run if it were sufficiently inefficient.

We explore the optimality of various exercise-price policies by developing a framework for measuring the value of, and incentives provided by, non-tradable executive (and employee) stock options. Our framework provides an alternative to traditional option pricing methodologies, which overestimate option values for risk-averse executiverecipients. We show that there is a fairly wide range of exercise pricing policies that yield close-to-optimal pay-to-performance incentives, and that this range typically includes grantdate market values. Risk-averse executives discount small probabilities of large option gains, and setting exercise prices at (or near) the grant-date market price maximizes incentives by ensuring a relatively high probability of ultimate payout. Our framework, developed and described more fully in Hall and Kevin J. Murphy (2000), has implications not only for exercise-price policies, but also for option repricings, exchanges of cash for stock-based compensation, and the design of bonus plans.

3 Under US accounting rules, as long as the exercise price and term are fixed in advance, the accounting charge for options equals the spread between the grant-date market price and exercise price. There is therefore no charge for at-the-money or premium options, but there is a charge for discount options (the grant-date spread) and indexed options (because the exercise price is not fixed in advance). Under US tax rules, options must have exercise prices at or above the grant-date price to qualify for favorable tax treatment; however, most top executives receive "non-qualified" options which are not subject to this restriction. 


\section{The Cost and Value of Executive Stock Options}

When valuing non-tradable executive stock options, it is critical to distinguish between two valuation concepts: the cost to the company, and the value to the executive-recipient. The economic or opportunity cost of granting an option is the amount the company could have received if it were to sell the option to an outside investor rather than giving it to the executive. The outside investor is generally free to trade the option, and can also take actions (such as short-selling the underlying stock) to hedge away the risk of the option. Fischer Black and Myron Scholes (1973) and Robert Merton (1973) demonstrated that, since investors can hedge, options can be valued as if investors were risk neutral and all assets appreciate at the risk-free rate. This risk-neutrality assumption forms the basis of option pricing theory and is central to all option pricing models, including binomial models, arbitrage pricing models, and Monte Carlo methodologies. ${ }^{4}$

In contrast to outside investors, company executives cannot trade or sell their options, and are also forbidden from hedging the risks by short-selling company stock. In addition, while outside investors tend to be well-diversified (holding small amounts of stock in a large number of companies), company executives are inherently undiversified, with their physical as well as human capital invested disproportionately in their company. For these reasons, company executives will generally place a much lower value on company stock options than would outside investors.

Ignoring complications related to early exercise, potential forfeiture, and executive inside information, option valuation formulas such as the Black-Scholes formula are

4 See John Hull (1993) for a comprehensive discussion of the various pricing models. 
appropriate for measuring the amount outside investors would pay for an option. ${ }^{5}$ However, the value of a non-tradable option to a risk-averse executive is more appropriately measured by the amount of riskless cash compensation the executive would exchange for the option. We estimate option values using the "certainty equivalence" approach, similar to that adopted by Richard Lambert, et. al. (1991). In particular, we suppose that an executive has non-firm-related wealth of $w$, holds $s$ shares of company stock, and is granted an option to buy one share of stock at exercise price $X$ in $T$ years. Assuming that $w$ is invested at the riskfree rate, $r_{f}$, and that the realized stock price at $T$ is $P_{T}$, the executive's wealth at time $T$ is given by $W_{T} \equiv w\left(I+r_{f}\right)^{T}+s P_{T}+\max \left(0, P_{T} X\right)$. If, instead of the option, he were awarded $V$ in cash invested at the risk-free rate, his wealth at time $T$ would be $W_{T}^{V} \equiv(w+V)\left(1+r_{f}\right)^{T}+s P_{T}$. We define the executive's value of the option as the certainty equivalent $V$ that equates

$$
\int U\left(W_{T}^{V}\right) f\left(P_{T}\right) d P_{T} \equiv \int U\left(W_{T}\right) f\left(P_{T}\right) d P_{T}
$$

To solve (1) numerically, we assume the executive has constant relative risk aversion $\rho$, and assume (using the Capital Asset Pricing Model, CAPM) that the distribution of stock prices in $T$ years is lognormal with volatility $\sigma$ and expected value $\left(r_{f}+\beta\left(r_{m}-r_{f}\right)-\sigma^{2} / 2\right) T$, where $\beta$ is the firm's systematic risk and $r_{m}$ is the return on the market portfolio. ${ }^{6}$ The figures and numerical calculations in this article are derived assuming no dividends, $\sigma=.30, \beta=1, r_{f}$ $=6 \%$, and $r_{m}-r_{f}=6.5 \%$, but the qualitative results are not sensitive to (reasonable) changes in these parameters.

5 We relax these assumptions in Hall and Murphy (2000).

6 For tractability, we assume that the distribution of future stock prices is the same whether the executive receives options or cash. If the grant provides incentives that shift the distribution, and if the shift is not already incorporated into stock prices as of the grant date, we will underestimate both the cost and value of the option. Since our results hinge on the difference between (rather than the levels of) cost and value, we do not expect this assumption to affect our qualitative results. 
The value of an option from an executive's perspective depends on the usual BlackScholes parameters (exercise price, stock price, dividend yield, risk-free rate, and time until expiration) and also depends on managerial risk-aversion, wealth, and stockholdings. Our numerical analysis shows that the certainty-equivalent value is decreasing in risk aversion, increasing in non-firm-related wealth, and decreasing in holdings of company stock. Figure 1 illustrates the value of a ten-year non-tradable stock option with an exercise price of $\$ 30$. The realized payout is defined as the (positive) spread between the market and exercise price, and the Black-Scholes value, $C(P)$, approximates the company's cost of granting an option. The certainty equivalent is calculated as the amount of cash the executive would willingly give up to receive the option, assuming constant relative risk aversion of $\rho=2$, and assuming that all stock and options are held for ten years.

As shown in Figure 1, the "executive value" lines (which plot the certainty-equivalent values as a function of stock prices) lie strictly below the Black-Scholes line, $V(P)<C(P)$, indicating that risk-averse executives value non-tradable options at significantly less than their cost to the company. ${ }^{7}$ Moreover, executives with large holdings of company stock (relative to their wealth) place lower values on options. For example, when the stock price and exercise price are both $\$ 30$, the figure shows that the Black-Scholes value is $\$ 16.55$. In contrast, an executive with $33 \%, 50 \%$, and $66 \%$ of his wealth in company stock values the option at only $\$ 15.01, \$ 10.65$ and $\$ 7.49$, respectively. When the stock price is $\$ 15$ (i.e., the option is issued with an exercise price double the stock price), the Black-Scholes value is $\$ 4.95$, while the executive values are only $\$ 3.93, \$ 2.48$ and $\$ 1.58$ (for $33 \%, 50 \%$ and $66 \%$ of wealth in stock, respectively). 
Figure 1 and our subsequent analysis suggests that, while Black-Scholes may be appropriate for estimating the company's cost of granting an option, it is not appropriate for estimating the value an executive places on a non-tradable option. Moreover, the ratio of the Black-Scholes cost to the executive's valuation is largest for options that are granted well out-of-the-money. Intuitively, options granted out-of-the-money are more likely to expire unexercised than options granted in the money. For example, based on the CAPM and company parameters assumed above, an option granted at-the-money will be in-the-money at expiration with $80 \%$ probability. In contrast, an option with an exercise price double the grant-date market price will be in-the-money at expiration with $50 \%$ probability; setting the exercise price to triple the grant-date price reduces the exercise probability to only $35 \%$. Risk-averse executives will discount payouts realized with low probabilities, and the wedge between Black-Scholes and executive values will be larger for out-of-the-money options.

\section{Incentives from Executive Stock Options}

Stock options provide a direct link between executive expected utility and shareholder wealth. Assuming executives understand how their actions affect share prices, option holdings provide incentives for executives to take actions that increase share prices, and avoid actions that decrease share prices. ${ }^{8}$ The incentives from a single option will naturally depend on the slope of the executive-value line, $\partial V / \partial P$, which defines how the certaintyequivalent value changes with an incremental change in the stock price. As illustrated in figure 1, the slope of the executive-value line is less than the slope of the Black-Scholes line,

$7 \quad$ The executive-value line can actually lie above the Black-Scholes line when executives are sufficiently diversified and have sufficiently low risk aversion. 
$\partial C / \partial P$, for undiversified executives. For example, when the stock price and exercise price are both $\$ 30$, the slope of the Black-Scholes function is 0.86 (86 per $\$ 1$ price change), but the slope of the executive-value line is only 0.64 for an executive with $50 \%$ of his wealth in company stock. For a premium option granted with $\mathrm{P}=\$ 15$ and $\mathrm{X}=\$ 30$, the Black-Scholes slope is 0.63 compared to an executive-value slope of only 0.38 for the same executive.

Figure 1 illustrates the trade-off faced by the board when setting exercise prices for executive options: increasing the exercise price, $X$, reduces the incentives of each option granted, $\partial V / \partial P$, but also reduces the company's cost of granting each option, $C$. In other words, holding the company's total cost of granting $n$ options constant, $n C=k$, the company could grant a few options at a low exercise price, or more options at a higher exercise price. For example, suppose that a company's stock price is $\$ 30$, and that the board has decided to award the executive $\$ 500,000$ in options. The company could award the executive 16,667 shares of restricted stock (essentially options with a zero exercise price). Alternatively, based on our maintained assumptions regarding dividend yield, volatility, etc., the company could award 30,200 at-the-money options (with a Black-Scholes value of $\$ 16.55$ each) or 50,500 premium options with an exercise price of $\$ 60$ (with a Black-Scholes value of $\$ 9.90$ each).

The company's optimization problem contains two steps. First, we fix the total cost of options to $k$, and solve for the exercise price, $\mathrm{X}$, that maximizes incentives, $\partial n V / \partial P$. Second, we find the grant-size, $k$, that maximizes company value. The first step solves,

$$
\underset{X}{\operatorname{MAX}} \partial n V / \partial P, \text { subject to } n C=k
$$

The incentive-maximizing exercise price, $X^{*}$, will depend on the usual arguments in the

8 Stock options may also provide incentives to encourage risk-taking, to avoid dividends, and to favor 
Black-Scholes function and will also depend on other factors that affect $\partial n V / \partial P$, such as the degree of risk aversion, wealth, previously owned stock, and the number of options to be granted. The second step, determining the value-maximizing grant size, depends on the (unmodeled) production function linking executive actions to company value. Although solving this second step is beyond the scope of this article, we show that $X^{*}$ is relatively constant through a wide range of grant sizes.

Figure 2 depicts total managerial incentives from an option grant with a Black-Scholes value of $\$ 500,000$ (assumed to be $10 \%$ of his initial $\$ 5$ million wealth). Incentives are defined as $2 n V / \partial P$ and measure the change in the certainty equivalent values of $n$ options for each $\$ 1$ change in stock prices; assumptions regarding risk-aversion, etc., are maintained from Figure 1. The figure shows that the incentives for an executive with $50 \%$ of his wealth in company stock are maximized by setting an exercise price equal to $110 \%$ of the market price of the stock on the date of grant. Importantly, the incentive loci are relatively flat around the maximum: $\partial n V / \partial P$ is within $1 \%$ of its maximum in range of exercises prices between $90 \%$ and $140 \%$ of the grant-date stock price. Similarly, the incentives for an executive with $66 \%$ of his wealth in company stock are maximized at an exercise price of only $80 \%$ of the grant date market price. Again, the incentive loci are relatively flat around the maximum; exercise prices in the range of $60 \%$ to $80 \%$ of the stock price generate incentives within $1 \%$ of the maximum.

In addition to showing how executive incentives vary with changes in the exercise price, Figure 2 also shows how the Black-Scholes' slope of options costing $n C=k$ vary with the exercise price. The figure shows that $\partial n C / \partial P$ is monotonically increasing throughout the 
depicted range; in fact, $\partial n C / \partial P$ is monotonically increasing for all exercise prices. The result suggests that, if managers valued stock options at their Black-Scholes value, the optimal granting policy would be to grant an infinite number of options at an infinite exercise price. The absurdity of this result underscores the need to introduce managerial risk aversion into any analysis of executive stock option valuations and incentives.

Table 1 shows the range of incentive-maximizing exercise prices for executives with different option-grant amounts, diversification, and risk-aversion. The incentive-maximizing range is defined as the exercise prices that generate incentives, $\partial_{n} V / \partial P$, within $1 \%$ of its maximum. The table shows that the optimal range is lower for large grants (as a percentage of wealth), and is also lower for less-diversified and more risk-averse executives. The analysis suggests that, for the range of parameters explored in Table 1, setting exercise prices at (or near) the grant-date market price maximizes pay/performance incentives for riskaverse, undiversified executives. In the few cases in which the incentive-maximizing range does not include at-the-money options, the incentives provided by at-the-money options are within a few percentage points of the maximum because of the flatness of the curves.

Our results show that, holding constant the company's cost of making an option grant, incentives are maximized by setting exercise prices within a range that typically includes the grant-date market price. Executive value, however, is maximized by setting the exercise price as low as possible. We believe that US accounting rules, which require some accounting charges for discount options, help explain why exercise prices are seldom set below grant-date market prices. Our analysis suggests that, in general, avoiding the accounting charge is not likely to be very costly to companies in terms of providing incentives. That is, even in cases where the optimal grant is a discount option, granting at- 
the-money options instead of discount options provides incentives that are nearly as strong.

\section{Extensions and Conclusions}

Executive pay practices are subject to intense public scrutiny, especially when they deviate from established precedent. Although the desire to avoid publicity can explain why companies adopt similar option terms (such as granting all options at the money), we would not expect the practice to survive if it systematically yielded sub-optimal incentives. We offer an economic rationale for the observed practice, by showing that pay-to-performance incentives for risk-averse, undiversified executives are typically maximized by setting exercise prices at (or near) the grant-date market price.

More generally, we have provided an operationally useful alternative to Black-Scholes for the purpose of both valuing stock options and measuring the incentives created by such options. Black-Scholes values measure the company's cost of granting an option, but do not measure the value of the non-tradable option to a risk-averse executive. This result helps explain why executives so often argue that Black-Scholes valuation estimates are "too high," and why they demand large premiums for accepting stock options in lieu of cash compensation. The result also helps explain why companies feel such pressure to reprice when their options go "underwater." Because these options have such a high probability of expiring out of the money, risk-averse executives place very little value on them (much lower than the value implied by Black-Scholes calculations), and they therefore provide very weak incentives. In addition, our analysis helps explain why firms rarely grant premium options, and a slight extension of our analysis helps explain the paucity of indexed option plans. In particular, indexed options issued at-the-money have a payout probability of only 
$50 \%$, which, according to our analysis, is generally too low to provide meaningful incentives for risk-averse executives. ${ }^{9}$

Our results also have implications for academic research that adds options values to other risky components of pay to establish "total compensation." At best, this aggregate calculation is a measure of the company's cost of the compensation package, and not an estimate of the executive's value of the compensation package. Finally, our analysis offers some general implications for the design of employee bonus plans. Human resource practitioners often claim that incentive plans are most effective when there is a relatively high probability that employees receive at least some payout. We explicitly model the incentives from stock option contracts, and find that, holding the expected cost of the payouts constant, incentives for risk-averse employees are maximized when the probability of a payout is reasonably high.

\footnotetext{
Measuring performance relative to an index can have the desirable effect of protecting executives from market- and industry-wide shocks. But indexing the exercise price of an option on average raises the performance threshold (through general market appreciation) as well as changes the implicit performance measure to a relative measure. The increased threshold leads to sub-optimally low payout probabilities unless the option is sufficiently discounted at grant.
} 


\section{References}

Black, Fischer and Scholes, Myron. "The Pricing of Options and Corporate Liabilities," Journal of Political Economy, 1973, 81, 637-59.

Hall, Brian J. and Leibman, Jeffrey B. “Are CEOs Really Paid Like Bureaucrats?" Quarterly Journal of Economics, 1998, 113(3): 653-691.

Hall, Brian J. and Murphy, Kevin J. "Stock Options for Undiversified Executives," mimeo, Harvard Business School, January 2000.

Hull, John. Options, Futures, and Other Derivative Securities, 2nd Edition, Prentice Hall: New Jersey, 1993.

Lambert, Richard A.; Larcker, David F. and Verrecchia, Robert E., "Portfolio Considerations in Valuing Executive Compensation," Journal of Accounting Research, 1991, 29(1), 12949.

Merton, Robert C., "Theory of Rational Option Pricing," Bell Journal of Economics and Management Science, IV, 1973, 141-183.

Murphy, Kevin J.. "Executive Compensation," in Orley Ashenfelter and David Card, eds., Handbook of Labor Economics, Vol. III, North Holland, 1999.

Rappaport, Alfred, "New Thinking on How to Link Executive Pay with Performance," Harvard Business Review, March/April 1999, 91-101. 


\section{Figure 1}

\section{Executive Value Lines: Option Values for Undiversified Executives}

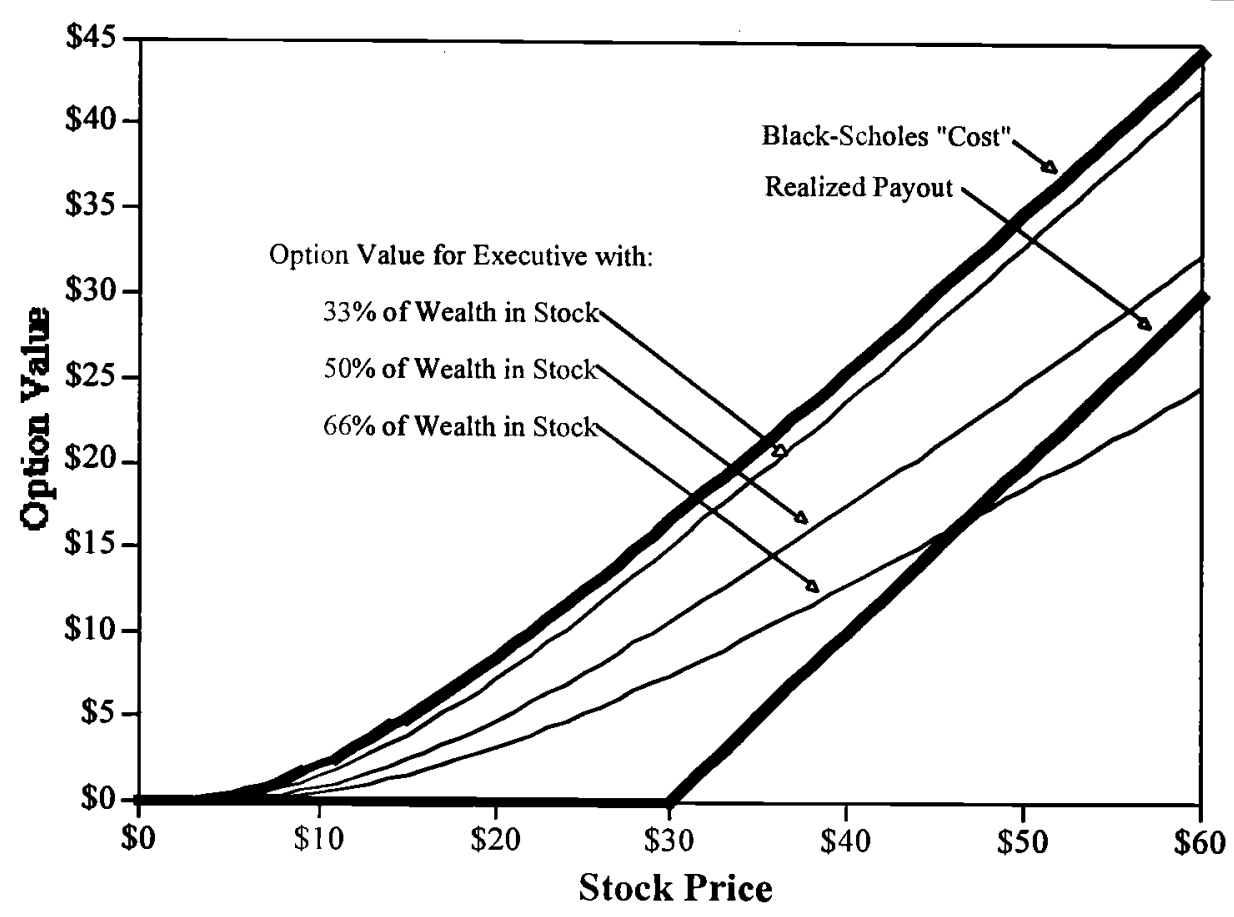

Figure 2

Incentive-Maximizing Exercise Prices

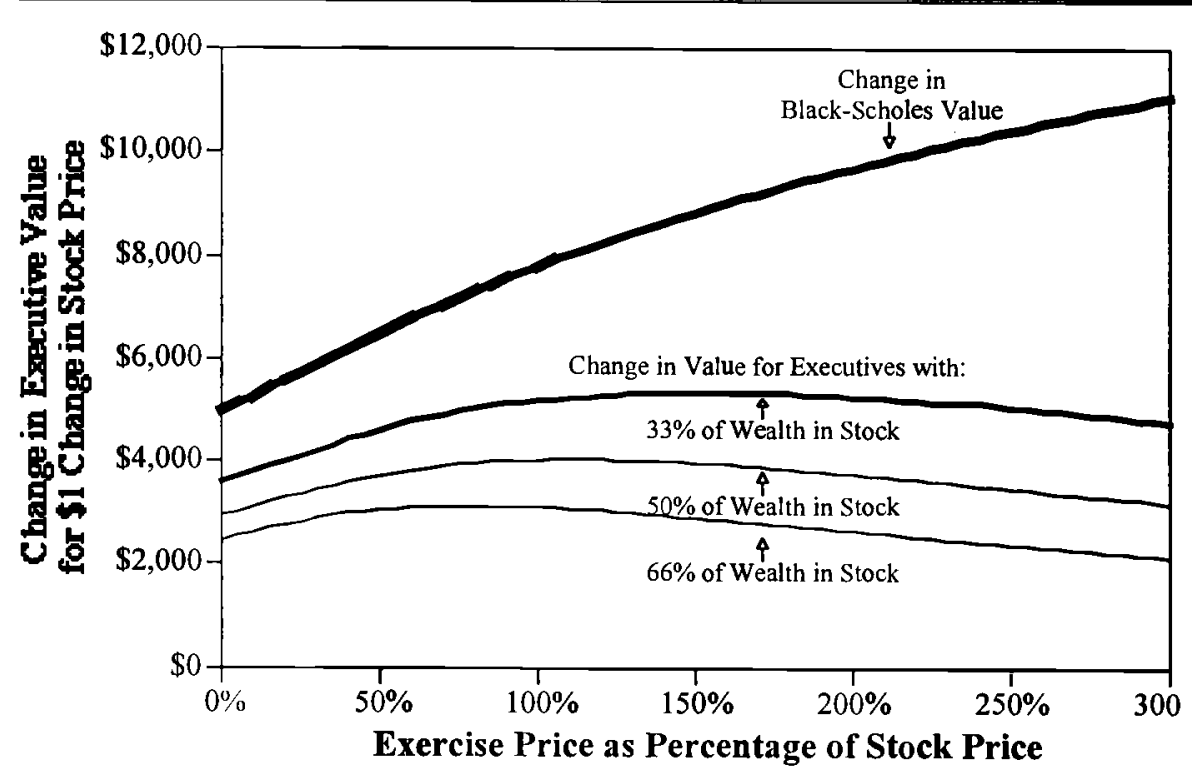

Note: The figure assumes that executives are granted stock options with a Black-Scholes value of $10 \%$ of initial wealth. We define "incentives" as the change in the certainty-equivalent option value for each $\$ 1$ change in the stock price. 
Table 1

Incentive-Maximizing Ranges of Exercise Prices

\begin{tabular}{|c|c|c|c|}
\hline $\begin{array}{l}\% \text { of Wealth Granted } \\
\text { in Stock Options }\end{array}$ & $\begin{array}{l}\% \text { of Wealth held in } \\
\text { Company Stock }\end{array}$ & $\begin{array}{c}\text { Executive } \\
\text { Risk Aversion }\end{array}$ & $\begin{array}{l}\text { Optimal Exercise Price } \\
\text { Range as \% of Stock Price }\end{array}$ \\
\hline $10 \%$ & $33 \%$ & 2.0 & $125 \%-185 \%$ \\
\hline $10 \%$ & $50 \%$ & 2.0 & $90 \%-140 \%$ \\
\hline $10 \%$ & $66 \%$ & 2.0 & $60 \%-100 \%$ \\
\hline $10 \%$ & $33 \%$ & 3.0 & $70 \%-105 \%$ \\
\hline $10 \%$ & $50 \%$ & 3.0 & $45 \%-70 \%$ \\
\hline $10 \%$ & $66 \%$ & 3.0 & $30 \%-45 \%$ \\
\hline $15 \%$ & $33 \%$ & 2.0 & $110 \%-160 \%$ \\
\hline $15 \%$ & $50 \%$ & 2.0 & $80 \%-120 \%$ \\
\hline $15 \%$ & $66 \%$ & 2.0 & $55 \%-90 \%$ \\
\hline
\end{tabular}

Optimal Range defined as exercise prices that generate total incentives, $\hat{\sigma}_{n} V / \partial P$, within $1 \%$ of the maximum incentives. 